\title{
Influence of the Cement Stabilized Macadam Base Modulus Change on the Mechanical Properties of Asphalt Pavement under Heavy Load
}

\author{
Zhaohui SUN ${ }^{1,}$ a Gang $\mathrm{CHEN}^{2, b}$ Tiebin Wang ${ }^{3, \mathrm{c}}$ Zhanqiang HOU ${ }^{4, \mathrm{~d}}$ \\ ${ }^{1}$ School of Civil Engineering, Shenyang Jianzhu University, Shenyang, 110168, China \\ ${ }^{2}$ Science and Technology Research Institute of Shenyang Railway Bureau, Shenyang, China \\ ${ }^{3}$ Liaoning Provincial Traffic Engineering Quality and Safety Supervision Bureau, Shenyang, China \\ ${ }^{4}$ Dalian Highway Engineering Group Co. Ltd. , Dalian, 116100, China \\ aemail: happyforevernicety@126.com, bemail:gangch@126.com, \\ cemail Tiebinw@126.com, ${ }^{\mathrm{d} H o u z h q @ 126 . c o m ~}$
}

Keywords: Heavy load; cement stabilized macadam; modulus; asphalt pavement; performance

\begin{abstract}
. the elastic plastic theory and finite element software are applied to analyze the stress of semi-rigid asphalt pavement structure of highway under different wheel load. The influences of modulus variation of cement stabilized macadam base on tensile stress at the bottom of layer, shear stress of surface layer and the surface deflection of the pavement structure under different wheel pressure are drawn for reference.
\end{abstract}

\section{Introduction}

More and more smoothness and comfort requirements are put up for road pavement with the increase of traffic volume, load, road grade and the improvement of people's living standard. The road surface deflection decreases. Cement stabilized macadam base can adapt to the heavy traffic and heavy axle load because of the characteristics of high strength, good stability, and is generally adopted in the asphalt pavement structure of semi rigid base course material of high grade highway in our country. However, the national highway survey found that there are still some early damages even if the pavement materials are designed completely according to the requirements of asphalt pavement design specification, the base material strength is not the higher the better. The influences of modulus variation of cement stabilized macadam base on tensile stress at the bottom of layer, shear stress of surface layer and the surface deflection of the pavement structure under different wheel pressure are researched to provide the reference for the reasonable modulus value range of cement stabilized macadam base.

\section{Model overload resolution}

In recent years, not only the growth of the traffic volume of China's automobile transportation is fast, but also axial load increase rapidly, heavy vehicles, especially large amplitude transfinite transport vehicles increased more significantly, such as vehicles for the 15 main highways in Shanghai area weighing survey found, the maximum axle load of overloading vehicles can reach $170 \mathrm{kN}$ (single shaft wheel pressure is $1.2 \mathrm{MPa}$ ), double shaft is up to $320 \mathrm{kN}$ (wheel pressure is $1.1 \mathrm{MPa}$ ), the truck above medium-sized is about $25 \%-45 \%$ overloaded.

In this paper, in order to determine the suitable heavy load to research the mechanics characteristics of semi-rigid pavement structure under heavy load, the mechanics responses are analyzed by modeling under the wheel pressure of $0.7 \mathrm{MPa}, 0.9 \mathrm{MPa}, 1.1 \mathrm{MPa}, 1.3 \mathrm{MPa}, 1.5 \mathrm{MPa}$.

Pavement structure scheme and design parameters are shown in Table 1 


\section{Model building}

Semi-rigid pavement structure is shown in Table 1.

The pavement structure model of $3.75 \mathrm{~m} \times 3.75 \mathrm{~m} \times 3.75 \mathrm{~m}$ is established to simulate the load response of pavement structure by calculation and analysis. The $\mathrm{X}$ axis direction is assumed as the traffic direction, $\mathrm{Z}$ axis direction is cross-sectional direction of pavement, $\mathrm{Y}$ axis direction is perpendicular to the road surface. The boundary constraint is shown in Figure 1 . The displacements of $\mathrm{X}$ axis direction and rotating around the $\mathrm{Y}$ axis, $\mathrm{Z}$ axis are constraint on the $\mathrm{X}$ axis plane, the displacements of $\mathrm{Z}$ axis direction and rotating around the $\mathrm{X}$ axis, $\mathrm{Y}$ axis are constraint on the $\mathrm{Z}$ axis plane (i.e., left and right surface), all constraints are arranged at the bottom of model. Due to the road surface stress of pavement structure model is complex, in order to improve accuracy on the mesh model, C3D4 free cells are used to divide surface course and C3D8R structural units are taken to divide the rest.The material modulus parameters for modeling are selected according to the recommended value by "Specifications for Design of Highway Asphalt Pavement" (JTG D50-2006), ${ }^{[2]}$ which is shown in Table 1

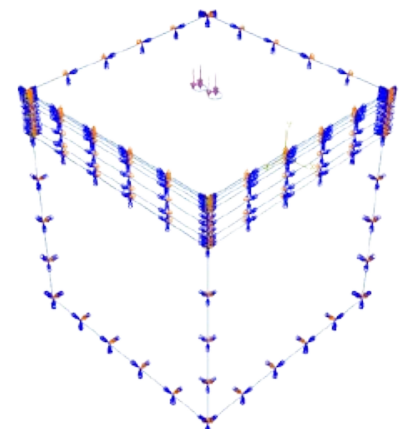

Figure 1 Boundary conditions of mode

Table 1 Pavement structure scheme and design parameters

\begin{tabular}{|c|c|c|c|}
\hline Pavement structure 1 & $\begin{array}{l}\text { Compressive (tensile) } \\
\text { modulus / } \mathrm{MPa}\end{array}$ & Pavement structure 2 & $\begin{array}{c}\text { Compressive (tensile) } \\
\text { modulus /MPa }\end{array}$ \\
\hline $\begin{array}{lll}\text { Surface } & \text { course } & 4 \mathrm{~cm} \\
\text { SMA13 } & & \end{array}$ & 1800 & $\begin{array}{lll}\text { Surface } & \text { course } & 4 \mathrm{~cm} \\
\text { AC-13 } & & \end{array}$ & 2000 \\
\hline $\begin{array}{l}\text { Intermediate } \text { course } 5 \mathrm{~cm} \\
\text { LAC-20 }\end{array}$ & 1800 & $\begin{array}{lll}\text { Intermediate course } 6 \mathrm{~cm} \\
\text { AC-20 }\end{array}$ & 1800 \\
\hline $\begin{array}{l}\text { Underlying course } 7 \mathrm{~cm} \\
\text { LAC-25 }\end{array}$ & 1200 & $\begin{array}{lll}\text { Underlying course } 8 \mathrm{~cm} \\
\text { AC-25 }\end{array}$ & 1200 \\
\hline $\begin{array}{l}\text { Base course } 20 \mathrm{~cm} \text { cement } \\
\text { stabilized macadam }\end{array}$ & $1500(3600)$ & $\begin{array}{l}\text { Base course } 20 \mathrm{~cm} \text { cement } \\
\text { stabilized macadam }\end{array}$ & $1500 （ 3500 ）$ \\
\hline $\begin{array}{l}\text { Subbase course } 20 \mathrm{~cm} \\
\text { cement stabilized macadam }\end{array}$ & 1500（3600） & $\begin{array}{l}\text { Subbase course } 20 \mathrm{~cm} \\
\text { cement stabilized macadam }\end{array}$ & 1500（3500） \\
\hline Cushion16cm gravel & 175 & Cushion12cmMedium sand & 100 \\
\hline Subgrade & 35 & Subgrade & 50 \\
\hline
\end{tabular}

\section{Analysis of calculation results}

The tensile stress at the bottom of pavement structure layers, shear stress of surface course and deflection can be respectively calculated under the action of wheel pressure of $0.7 \mathrm{MPa}, 0.9 \mathrm{MPa}$, 1.1MPa, 1.3MPa, 1.5MPa by using elastic plastic theory and finite element software when modulus of cement stabilized macadam base are respectively $1500 \mathrm{MPa}$ and $3600 \mathrm{MPa}$ (the design value) in pavement structure 1, the calculation results are seen in Table 2 and table 3 . The tensile stress at the bottom of pavement structure layers, shear stress of surface course and deflection can be calculated when modulus of cement stabilized macadam base are respectively $1500 \mathrm{MPa}$ and $3500 \mathrm{MPa}$ (the design value) in pavement structure 2, the calculation results are shown in Table 4 and table 5 
Table 2 The calculation results of structure 1(cement stabilized macadam modulus is $1500 \mathrm{MPa}$ )

\begin{tabular}{|c|c|c|c|c|c|}
\hline Load & $0.7 \mathrm{MPa}$ & $0.9 \mathrm{Mpa}$ & $1.1 \mathrm{Mpa}$ & 1.3Mpa & $1.5 \mathrm{Mpa}$ \\
\hline Deflection $(0.01 \mathrm{~mm})$ & 24.88 & 31.85 & 38.67 & 45.57 & 52.68 \\
\hline $\begin{array}{l}\text { The maximum tensile stress of surface } \\
\text { course (Mpa) }\end{array}$ & 0.0308 & 0.0403 & 0.0486 & 0.0589 & 0.0675 \\
\hline $\begin{array}{l}\text { The maximum tensile stress of intermediate } \\
\text { course (Mpa) }\end{array}$ & 0.0253 & 0.0309 & 0.0372 & 0.0428 & 0.0487 \\
\hline $\begin{array}{l}\text { The maximum tensile stress of underlying } \\
\text { course (MPa) }\end{array}$ & 0.0134 & 0.0169 & 0.0198 & 0.0218 & 0.0247 \\
\hline $\begin{array}{l}\text { The maximum tensile stress of cement } \\
\text { stabilized macadam course (MPa) }\end{array}$ & 0.1182 & 0.1461 & 0.1764 & 0.2044 & 0.2463 \\
\hline $\begin{array}{l}\text { The maximum shear stress of surface } \\
\text { course (MPa) }\end{array}$ & 0.2175 & 0.2791 & 0.3407 & 0.4026 & 0.4622 \\
\hline
\end{tabular}

Table 3 The calculation results of structure 1 (cement stabilized macadam modulus is $3600 \mathrm{MPa}$ )

\begin{tabular}{|c|c|c|c|c|c|}
\hline Load & $0.7 \mathrm{MPa}$ & $0.9 \mathrm{MPa}$ & $1.1 \mathrm{MPa}$ & 1.3MPa & $1.5 \mathrm{MPa}$ \\
\hline Deflection $(0.01 \mathrm{~mm})$ & 20.15 & 27.16 & 33.96 & 40.89 & 48.06 \\
\hline $\begin{array}{l}\text { The maximum tensile stress of surface } \\
\text { course (Mpa) }\end{array}$ & 0.0218 & 0.0333 & 0.0418 & 0.0524 & 0.0612 \\
\hline $\begin{array}{l}\text { The maximum tensile stress of } \\
\text { intermediate course }(\mathrm{Mpa})\end{array}$ & 0.0133 & 0.0192 & 0.0264 & 0.0319 & 0.0375 \\
\hline $\begin{array}{l}\text { The maximum tensile stress of underlying } \\
\text { course (MPa) }\end{array}$ & 0.0083 & 0.0120 & 0.0149 & 0.0169 & 0.0200 \\
\hline $\begin{array}{l}\text { The maximum tensile stress of cement } \\
\text { stabilized macadam course (MPa) }\end{array}$ & 0.1418 & 0.1732 & 0.2123 & 0.2455 & 0.2968 \\
\hline $\begin{array}{l}\text { The maximum shear stress of surface } \\
\text { course }(\mathrm{MPa})\end{array}$ & 0.2096 & 0.2641 & 0.3331 & 0.3951 & 0.4548 \\
\hline
\end{tabular}

As can be seen From table 2 and table 3, the road surface deflection value, the maximum shear stress of surface course and the maximum tensile stress of structure layers were increased with the increase of load in pavement structure 1 . When the modulus of cement stabilized macadam base increases from 1500MPa to 3600MPa, the road surface deflection value, the maximum shear stress of surface course and the maximum tensile stress of surface layers decreased correspondingly under the same loads, and with the increase of load, the magnitude decreases progressively. The maximum tensile stress of cement stabilized macadam base increases with the increase of load and its modulus, when the tire ground pressure are respectively $0.7 \mathrm{MPa}, 0.9 \mathrm{MPa}, 1.1 \mathrm{MPa}, 1.3 \mathrm{MPa}, 1.5 \mathrm{MPa}$, the maximum tensile stress at the bottom of cement stabilized macadam base when its modulus value is $3600 \mathrm{MPa}$ is 1.2 times than that of $1500 \mathrm{MPa}$. The multiple impacted by load change is smaller, that impacted by its modulus change is larger. By the analysis results, the increase of semi-rigid base modulus can effectively reduce the maximum tensile stress of asphalt surface layer and decrease the vertical deformation of the pavement surface, enhance the overall strength of the asphalt pavement, but the cement stabilized macadam base should have enough tensile strength which is required to avoid the crack and deformation.

As can be seen in table 4 and table 5, the road surface deflection value, maximum shear stress of surface layer and the maximum tensile stress of each layer were increased with the increase of load. When the modulus of cement stabilized macadam base increased from $1500 \mathrm{MPa}$ to $3500 \mathrm{MPa}$, the road surface deflection value, maximum shear stress of surface layer and the maximum tensile stress of surface layers is reduced, and the maximum shear stress of the surface layer is less affected by the change of the cement stabilized macadam base modulus, the maximum tensile stress at the bottom of cement stabilized macadam base when its modulus value is $3500 \mathrm{MPa}$ is 0.99 times than that of $1500 \mathrm{MPa}$. The change of shear stress caused by the change of cement stabilized macadam base modulus is tiny, the increasing amplitude of maximum shear stress of surface layer decreases 
gradually with the increase of load. The increases of the load have larger effects on the maximum tensile of surface layer and the road surface deflection value when the modulus of cement stabilized macadam base is larger. The tensile stress and the strength of pavement structure are sensitive to change of load and heavy load, while the shear stress of surface layer and the tensile stress of semi rigid base are second sensitive.

Table 4 The calculation results of structure 2(cement stabilized macadam modulus is $1500 \mathrm{MPa}$ )

\begin{tabular}{|c|c|c|c|c|c|}
\hline Load & $0.7 \mathrm{MPa}$ & $0.9 \mathrm{MPa}$ & $1.1 \mathrm{MPa}$ & 1.3MPa & $1.5 \mathrm{MPa}$ \\
\hline Deflection（0.01mm） & 22.99 & 29.55 & 36.12 & 42.69 & 49.12 \\
\hline $\begin{array}{l}\text { The maximum tensile stress of surface } \\
\text { course (Mpa) }\end{array}$ & 0.0289 & 0.0372 & 0.0448 & 0.0531 & 0.0612 \\
\hline $\begin{array}{l}\text { The maximum tensile stress of } \\
\text { intermediate course }(\mathrm{Mpa})\end{array}$ & 0.0199 & 0.0255 & 0.0312 & 0.0369 & 0.0417 \\
\hline $\begin{array}{l}\text { The maximum tensile stress of underlying } \\
\text { course }(\mathrm{MPa})\end{array}$ & 0.0097 & 0.0124 & 0.0152 & 0.0179 & 0.0202 \\
\hline $\begin{array}{l}\text { The maximum tensile stress of cement } \\
\text { stabilized macadam course ( } \mathrm{MPa})\end{array}$ & 0.1063 & 0.1366 & 0.1671 & 0.1974 & 0.2338 \\
\hline $\begin{array}{l}\text { The maximum shear stress of surface } \\
\text { course }(\mathrm{MPa})\end{array}$ & 0.2154 & 0.2769 & 0.3385 & 0.4002 & 0.4613 \\
\hline \multicolumn{6}{|c|}{ Table 5 The calculation results of structure 2(cement stabilized macadam modulus is $3500 \mathrm{MPa}$ ) } \\
\hline Load & $0.7 \mathrm{MPa}$ & $0.9 \mathrm{MPa}$ & $1.1 \mathrm{MPa}$ & $1.3 \mathrm{MPa}$ & $1.5 \mathrm{MPa}$ \\
\hline Deflection $(0.01 \mathrm{~mm})$ & 17.48 & 23.95 & 31.30 & 37.57 & 44.32 \\
\hline $\begin{array}{l}\text { The maximum tensile stress of surface } \\
\text { course (Mpa) }\end{array}$ & 0.0195 & 0.0283 & 0.0355 & 0.0437 & 0.0522 \\
\hline $\begin{array}{l}\text { The maximum tensile stress of intermediate } \\
\text { course (Mpa) }\end{array}$ & 0.0116 & 0.0172 & 0.0218 & 0.0284 & 0.0336 \\
\hline $\begin{array}{l}\text { The maximum tensile stress of underlying } \\
\text { course (MPa) }\end{array}$ & 0.0066 & 0.0089 & 0.0127 & 0.0148 & 0.0174 \\
\hline $\begin{array}{l}\text { The maximum tensile stress of cement } \\
\text { stabilized macadam course ( } \mathrm{MPa})\end{array}$ & 0.1298 & 0.1675 & 0.2031 & 0.2415 & 0.2869 \\
\hline $\begin{array}{l}\text { The maximum shear stress of surface course } \\
\text { (MPa) }\end{array}$ & 0.2128 & 0.2742 & 0.3356 & 0.3982 & 0.4588 \\
\hline
\end{tabular}

The maximum tensile stress of cement stabilized macadam base increases with the increase of load and its modulus, when the tire ground pressure are respectively $0.7 \mathrm{MPa}, 0.9 \mathrm{MPa}, 1.1 \mathrm{MPa}, 1.3$ $\mathrm{MPa}, 1.5 \mathrm{MPa}$, the maximum tensile stress at the bottom of layer when the modulus of cement stabilized macadam base is $3500 \mathrm{MPa}$ is 1.22 times than that of $1500 \mathrm{MPa}$.Its multiple was less influenced by load change than the modulus change of semi-rigid base. By the results of analysis, increasing the modulus of semi-rigid base can effectively reduce the maximum tensile stress of asphalt surface layer, decrease the vertical deformation of the pavement surface and enhance the overall strength of asphalt pavement, it is required that cement stabilized macadam base should have enough tensile strength to avoid the crack deformation.

\section{Conclusion}

The structure layer modulus and the thickness of material are not the same, the role of cement stabilized macadam base in the pavement is similar in the above two kinds of semi rigid asphalt pavement structure, mainly as follows:

Road surface deflection value, maximum shear stress of surface layer and the maximum tensile stress of structure layer were increased with the increase of load.

The change of surface layer shear stress caused by the change of the modulus of cement stabilized macadam base is tiny under the same loads, and with the increase of load, the increased rate of the surface layer maximum shear stress decreases gradually.

The increase of the load has larger impact on the maximum tensile of structure layer and the deflection of road surface when the modulus of cement stabilized macadam base is large. It shows 
that the tensile stress and the strength of pavement structure is more sensitive to the change of load and heavy load than the surface shear stress.

Increasing the modulus of semi-rigid base can effectively reduce the maximum tensile stress of asphalt surface layer, decrease the vertical deformation of the pavement surface and enhance the overall strength of asphalt pavement, but the cement stabilized macadam base should have enou gh tensile strength was required to avoid crack and deformation.

\section{Acknowledgement}

The research was sponsored by the Nature Science Foundation of China (Project No. 51178278)

\section{References}

[1]Highway Science Research Institute of Communications Ministry"Standard Test Methods of Bitumen and Bituminous Mixtures for Highway Engineering” JTG E20-2011 [S]Beijing: China Communications Press, 2011

[2] Industry criterions of PRC: Specifications for Design of Highway Asphalt Pavement JTG D50-2006

[3] Industry criterions of PRC:Test Methods of Aggregate for Highway Engineering JTG E42-2005

[4]Zhuangzhuo, You Xiaochuan etc. The finite element analysis and application Based on ABAQUS[M].Beijing: Tsinghua University Press, 2009.

[5] Xu Zhihong, "The calculation of new building flexible pavement structure layer for city road,”[J].China Municipal Engineering. 1993.3 